\title{
Correction to: Knowledge of the Culture of Safety in Cholecystectomy (COSIC) Among Surgical Residents: Do We Train Them Well For Future Practice?
}

\author{
Vishal Gupta $^{1} \cdot$ Pawanindra Lal $^{2} \cdot$ Anubhav Vindal ${ }^{2} \cdot$ Rajdeep Singh $^{2} \cdot$ Vinay K. Kapoor $^{3}$
}

Published online: 18 February 2021

(C) Société Internationale de Chirurgie 2021

\section{Correction to:}

\section{World J Surg}

https://doi.org/10.1007/s00268-020-05911-6

In the original article the author names in Ref. 15 are incorrect. Following is the corrected reference:

\section{Reference}

15. Buddingh KT, Hofker HS, ten Cate Hoedemaker HO et al (2011) Safety measures during cholecystectomy: results of a nationwide survey. World J Surg 35:1235-1241. https://doi.org/10.1007/ s00268-011-1061-3

Publisher's Note Springer Nature remains neutral with regard to jurisdictional claims in published maps and institutional affiliations.

The original article can be found online at https://doi.org/10.1007/ s00268-020-05911-6.

Vishal Gupta

vggis@yahoo.co.in

1 Department of Surgical Gastroenterology, King George's Medical University, Lucknow, UP, India

2 Department of Surgery, Maulana Azad Medical College, University of Delhi \& Associated Lok Nayak Hospital, New Delhi, India

3 Department of Surgical Gastroenterology, Sanjay Gandhi Post-Graduate Institute of Medical Sciences, Lucknow, UP, India 